\title{
Research on the Relationship Between Animals and Human Under the Pandemic
}

\author{
Xinyi Ge \\ ${ }^{1}$ The Pennington School, Pennington, New Jersey,08534,United States \\ *Corresponding author. Email: 1430182886@qq.com
}

\begin{abstract}
The coronavirus broke out in 2019 and is prevalent in the world because it is highly contagious. The virus dramatically impacted the world no matter in economics or medicine. People still have to wear masks to prevent the spread of the disease. The essay investigates mainly the relationship between animals and humans. To attain more information, the author conducted a survey and collected more than 100 responses regarding lives of animals during the pandemic. Furthermore, the author selected some essays that investigated the topic deeply and provided answers from different perspectives. After examining a survey and other academic sources, the results showed that a minority of people do believe animals are dangerous in the pandemic and thus abandoned their pets. However, majority of people wished to adopt animals to accompany them in the quarantine in order to reduce the panic and loneliness. Therefore, people still maintained stable and peaceful relationships with animals regardless of misleading reports.
\end{abstract}

Keywords: Pets, COVID-19, Human, Relationship, Transmission

\section{INTRODUCTION}

At the end of 2019, a virus broke out in Wuhan China. Experts suspected that the origin of the virus was in the Huanan Seafood Wholesale market[1]. Even though the exact cause of corona virus remained uncertain, many people assumed that selling wild animals might be the reason. There were reports about people dumped their pets fearing that they will get corona virus[2]. Therefore, the relationship between human and pets under the pandemic would be a worthwhile topic to investigate. Technology, economics, and education are all heated topics that people discuss. On the contrary, issues related to animals or pets often are ignored by common people and experts. Therefore, the pandemic might be a good opportunity to attract more people's attention to the relationship between animals and humans. The topic needed to address those questions: how people feel about their pets during the pandemic and why they develop the idea that pets would get the virus. To attain answers to those questions, it is advisable to conduct a survey and gather information from some papers that aim at the issue from different perspectives. Therefore, by incorporating surveys and information from essays, people can have a more comprehensive insight into the issue. Many kinds of research focused on the vaccines, spread of the virus, and the future trend. However, more attention should be paid to the relationship between human and pets would reveal a unique aspect of the corona virus. The article is designed to redress lack of coverage and encourage more future researches in animal-human relations area[3].

\section{SURVEY ABOUT ANIMALS DURING THE PANDEMIC}

A report about a dog owner in Hong Kong first revealed that the relationship between pets and human might be worsened during the pandemic. On February 25, 2020, a dog owner in Hong Kong was tested positive and her dog was also tested positive. This situation suggested potential infection between human and animals existed, and pets can get corona virus. The reports thus caused panic between pet owners and resulted in abandonment of pets. Many pets were discarded by pet owners in Wuhan because of the report[4]. The author then decided to investigate how animals' lives were under the corona virus and the report and if other people have the same idea. To gather data about pets under pandemic, the author conducted a survey containing 9 multiple questions. In order to get rid of biases, the author randomly selected 20 people 
from her Wechat friends list to answer the survey. In addition, the author also randomly selected 8 people and then asked them to ask 11 people from their friends' list to complete the survey. Therefore, the survey would have enough respondents and people in various places may provide totally different responses. From 108 responses the author gathered, only less than one-third of the respondents claimed that they see more stray animals during the pandemic. On the contrary, more than one-third of the respondents claimed that there was no marked increase in stray animals. It is uncertain that those animals were discarded by people fearing that they might catch a disease from pets, even if there was an increase in stray animals. In addition, 74 percent of respondents insisted that bacteria might be the reason others refuse to adopt stray animals. Almost 50 percent of respondents declared that limited knowledge about stray animals might be the cause. From the statistics, it is reasonable to assume that those people who discarded their cats during the pandemic might have the same concern. Furthermore, almost 60 percent of respondents believed that virus would parasitize on pets and then spread to people. It is reasonable to conclude that people during pandemic did fear that their pets would get corona virus. However, no definite conclusions should be made as it only contained 108 samples and the survey did not necessarily get rid of bias effect. Overall, the report suggested that the human-pet relationship might be worsened, while the survey did not provide any clear answer. Great proportions of people had a panic that pets might transmit virus, but it does not necessarily ensure that they would discard their pets.

Table 1: Response of whether number of stray animals increased during the pandemic

\begin{tabular}{|c|c|c|}
\hline & Number & Proportion \\
\hline Yes & 31 & $28.7 \%$ \\
\hline No & 41 & $37.96 \%$ \\
\hline Don't know & 36 & $33.33 \%$ \\
\hline Total & 108 & \\
\hline
\end{tabular}

Table 2: Response of whether people believe virus would parasitize on pets and then spread to human

\begin{tabular}{|c|c|c|}
\hline & Number & Proportion \\
\hline No & 23 & $21.3 \%$ \\
\hline Yes & 64 & $59.26 \%$ \\
\hline
\end{tabular}

\begin{tabular}{|l|c|c|}
\hline Don't & 21 & \\
\hline know & $19.44 \%$ \\
\hline Total & 108 & \\
\hline
\end{tabular}

Table 3: Reasons of refusing to adopt stray animals

\begin{tabular}{|c|c|c|}
\hline & Number & Proportion \\
\hline $\begin{array}{c}\text { worry they might } \\
\text { carry bacteria } \\
\text { the adoption } \\
\text { procedure is } \\
\text { inconvenient }\end{array}$ & 80 & $74.07 \%$ \\
\hline $\begin{array}{c}\text { the breed is not } \\
\text { good }\end{array}$ & 30 & \\
\hline $\begin{array}{c}\text { do not know how to } \\
\text { adopt stray animals }\end{array}$ & 41 & \\
\hline do not know stray & 51 & $27.78 \%$ \\
\hline animals & & \\
\hline Total & 108 & $47.96 \%$ \\
\hline
\end{tabular}

\section{CURRENT KNOWLEDGE ABOUT ANIMALS IN VIRUS TRANSMISSION}

In March 2020, another confirmed case in animals happened in Hong Kong. There were other cases in Belgium, France, Germany, Russia, and America. In addition, hamsters are also capable of having virus and transmit to native hamsters. Those cases provided strong support for the theory that animals are likely to get the disease and transmit disease to other animals. It caused panic among pet owners, especially cat owners since cats are the most susceptible, while dogs are less susceptible[5]. As a result, not only humans are susceptible to the disease but also animals. However, no scientific data supports the theory that animals would pass corona virus to humans. Pet owners should be cautious when taking their pets outside and take some protective measures. Other pets like ferrets could also contract the disease and spread to other ferrets through direct contact and air. On the contrary, livestock animals typically are not susceptible to corona virus, such as horses, sheep, and cows. Other than domesticated animals, wild animals are also susceptible to the disease, like tigers and lions. In April 2020, five tigers and three lions exhibited symptoms and were tested positive in New York. The investigation revealed that an asymptomatic worker transmitted virus to those wild animals. Furthermore, first mink case happened in mink farms in Netherlands as some workers were tested positive before the mink. Other countries also reported similar cases of animal infection[5]. If pet owners or 
workers in the zoo do not take serious measures to prevent human to animal infection, negative impacts may affect animals. However, a recent case exhibited mink to human infection. After examining the viral sequences between the worker and the mink, great similarities were found. In addition, the mink could be asymptomatic, functioning as an intermediate host, infected the worker. Therefore, animal to animal, animal to human, and human to human are all possible ways for the disease to spread. Experts used animal models to study corona virus. The golden Syrian hamsters, ferrets, rhesus macaque, and African green monkeys all exhibited apparent symptoms and thus they were suitable models. In the experiment, the corona virus replicated efficiently in respiratory tract of animals for days without resulting in death[5]. Overall, people are recommended to keep their distance from animals once they have symptoms. According to the mink case, animals also have potentials to transmit disease to human. As a result, people should avoid unnecessary contact with animals to avoid or slow down the spread of the corona virus.

\section{MORE DOG ADOPTIONS DURING THE PANDEMIC}

While social distancing and isolation are effective in preventing spread of the disease, those measures might impact people's psychological states. In addition, quarantine might lead to lower quality of life and high-stress levels[6]. As a result, different than what the author expected, abandonment of pets, the number of people who adopted dogs actually increased during the pandemic as interactions with pets will help with depression. Raising pets has many advantages: providing companionship, improving social relationships, and strengthening feelings of trust and empathy among people. However, if pet owners' lives changed during the pandemic or behavioral problems developed in dogs, it might increase the possibility of abandonment of dogs. Theoretically, economic crisis, reports about animals have potentials to transmit disease, and general stress and panic would cause many cases of dog abandonment. To have a more accurate idea of human-pet relationship, a study was conducted to investigate how pandemics affected adoption and abandonment of dogs. The study used the Yad4, which is an Israel national database for dog adoption. Potential adopters could find available dogs and shelters through the website[6]. The number of abandoned dogs recorded on the Yad4 did not change dramatically. However, adoption rate was affected by different time periods. The average adoption requests were between 29.2 and 33 per day. During the lockdown, the number of requests were between 107.2 and 115.4 per day. The number of adoption requests in Israel was significantly higher than in China as the adoption requests were between 21.6 and 29.8 per day. Yad4 website also provided an option for people to be foster families. Usually, the demand far exceeds supply as there are a few foster families. However, the supply exceeded demand during the pandemic Similar situations also happened in China.iThe daily visitors on the Yad4 website were dramatically higher than data before the pandemic. According to media reports, a great number of people in other countries also wanted to adopt dogs and many pictures of empty cage were posted on the media. The study revealed that the concern of increased dog abandonment is not validated. People adopted dogs because three main reasons: reducing stress and loneliness, seeing reports about increased dog abandonment, and planning to get dogs even before the pandemic.[6]

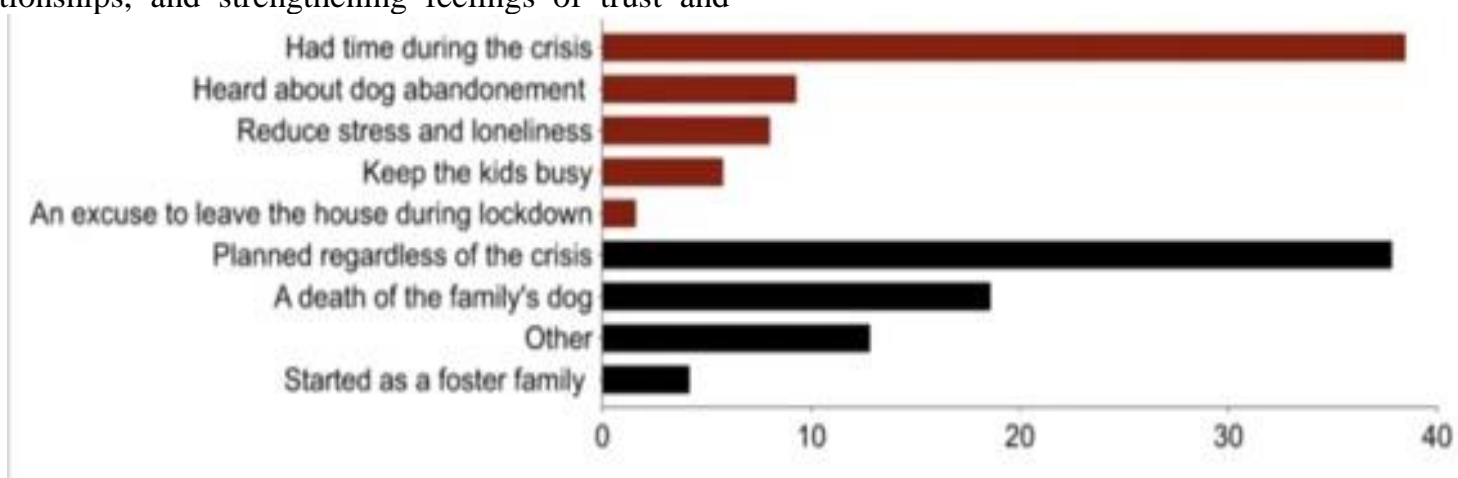

$\%$ Answered

Figure 1: reasons for dog adoptions during the covid-19 pandemic

\section{CONCLUSION}

During the pandemic, the society went through many changes, like economic loss, increasing unemployment rate, and mental issues. The topic of how animals and their lives get affected is hardly investigated by experts until reports claimed that more people abandoned their pets because of the corona virus. The essay consists of several body paragraphs to analyze if animals are capable of transmitting disease 
and how the relationship between human and animals changed during the pandemic. Noticeably, animals are capable of infecting virus and transmitting to other animals through direct contact or air. In addition, animals have possibility to transmit disease to people and thus people should keep distance from animals under the virus. The reports about increasing pet abandonment might be exaggerated. Even though some cases of pet abandonment existed, the number of dog adoptions increased during the pandemic. The essay might not be conclusive enough as it does not include more study or experiments done by experts. More definite conclusions could be made if supported by more data. Issues related to animals are often ignored by people. However, the pandemic might be a good opportunity for people to pay attention to stray animals or pets' mental issues. To help animals or strengthen the relationship between human and pets, more websites designed to help people adopt animals could be established. In addition, bloggers and celebrities should call for ban on pet's abandonment and organize more activities to help animals and attract their fans to be involved in helping those animals.

\section{REFERENCES}

[1] J Chin Med Assoc. 2020 Mar; 83(3): 217-220. Published online $2020 \quad$ Feb 12. doi: 10.1097/JCMA.0000000000000270

[2] Salzberger, B., Glück, T. \& Ehrenstein, B. Successful containment of COVID-19:the WHO-Report on the COVID-19 outbreak in China, 151-

153(2020).https://doi.org/10.1007/s15010-020-014 $09-4$

[3] Plous, S. (1993), The Role of Animals in Human Society.Journal of Social Issues, 49: 1-9. https://doi.org/10.1111/j.1540-4560.1993.tb00 906.x

[4] Journal of Travel Medicine, Volume 27, Issue 3, April 2020 , taaa046, https://doi.org/10.1093/jtm/taaa046

[5] Kiros, M., Andualem, H., Kiros, T. et al. COVID-19 pandemic: current knowledge about the role of pets and other animals in disease transmission. Virol J17,143(2020).https://doi.org/10.1186/s12985-02001416-9

[6] Morgan, L., Protopopova, A., Birkler, R.I.D. et al. Human-dog relationships during the COVID-19 pandemic: booming dog adoption during social isolation. Humanit Soc Sci Commun 7, 155 (2020). https://doi.org/10.1057/s41599-020-00649-x 